\title{
Guidelines for the prevention of secondary lymphedema following breast cancer treatment: adhesion and associated factors
}

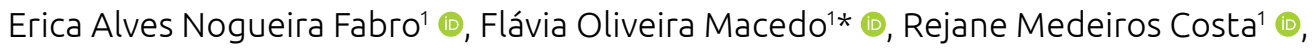

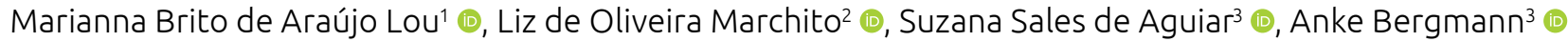

\section{ABSTRACT}

Introduction: Lymphedema is the most feared complication that may take place after breast cancer treatment. With treatment progression, doubts have arisen regarding the real benefits of lymphedema prevention care, as well as of patient adherence to guidelines. Objective: In this context, the aim of this study was to assess patient adherence to preventive lymphedema guidelines and the distribution of sociodemographic, clinical, and treatment variables according to adherence to treatment. Methods: A cross-sectional study conducted at the Cancer Hospital III/INCA, Rio de Janeiro, Brazil, concerning patients with breast cancer undergoing surgical treatment with an axillary approach. Participants were questioned about assistance care performance, exercise-related care, and limb ipsilateral to surgery care. A descriptive analysis of patient demographic, clinical, treatments, postoperative complications variables, and main outcomes (adherence to the guidelines) was performed through a central tendency measure and data dispersion and frequency measures analyses. Differences between means were assessed using the Student's t-test, while differences between proportions were evaluated using the chi-square test. A significance level of $5 \%$ was considered for all assessments. Results: Of the 103 women included in this study, $89.3 \%$ adhered to assistance care, 61.2\% adhered to limb care, and $42.7 \%$ performed exercise-related care. Women undergoing chemotherapy $(p=0.030)$ and axillary lymphadenectomy (AL) ( $p=0.017$ ) exhibited greater adherence to care. Non-white patients $(p=0.048)$ and those who underwent $\operatorname{AL}(p=0.025)$ adhered to limb care more frequently. Finally, patients displaying lower education levels $(p=0.013)$ and those who underwent AL ( $p=0.009$ ) adhered more frequently to limb exercises. Conclusion: Patients adhered the most to assistance care and limb care compared to exercise practice. Patients undergoing chemotherapy displayed greater adherence to care and non-white patients adhered the most to limb care. Women who underwent AL displayed greater adherence to all types of care and those presenting lower education levels adhered more frequently to exercise guidelines.

KEYWORDS: breast neoplasms; lymphedema; physical therapy modalities; disease prevention.

\section{INTRODUCTION}

Breast cancer is the most frequent type of tumor in the female population. Over 2 million new cases were estimated worldwide in 2020, and 66,000 new cases have been estimated every year in the 2020/2022 triennium in Brazil ${ }^{1,2}$. The estimated 5-year survival rate of patients undergoing breast cancer treatment in Brazil is of 75.2\% (73.9-76.5) from 2010 to 2014. Difficulties in accessing diagnostic methods and adequate treatment lead to the arrival of patients in more advanced stages of the disease and displaying worse prognoses ${ }^{3}$.

Tumor staging represents an important breast cancer prognostic factor. Therefore, early diagnosis during initial staging can lead to greater cure chances and lower treatment-associated morbidity. However, diagnoses in Brazil are still regularly performed in more advanced stages, requiring more aggressive therapeutic approaches and resulting in increased morbidity and increased

${ }^{1}$ Physiotherapy Department, Cancer Hospital III, Brazilian National Cancer Institute - Rio de Janeiro (RJ), Brazil.

2Physiotherapy Department, Samaritano Hospital - Rio de Janeiro (RJ), Brazil.

${ }^{3}$ Clinical Research Division, Brazilian National Cancer Institute - Rio de Janeiro (RJ), Brazil.

*Corresponding author: flaomacedo@gmail.com

Conflict of interests: nothing to declare.

Received on: 07/13/2021. Accepted on: 10/25/2021. 
incidence of functional, emotional, and social sequelae, directly compromising patient's quality of life ${ }^{4-6}$.

Lymphedema is the most feared complication in patients undergoing breast cancer treatment. This condition is manifested by the accumulation of water, proteins, and cellular products in the extracellular space due to lymphatic system insufficiency concerning lymph transport in the face of flow obstructions ${ }^{7,8}$.

The prevalence of lymphedema in patients undergoing an axillary surgical approach ranges from $0.4 \%$ to $92.5 \%$ and incidence between $5.9 \%$ and $56.7 \%$, depending on the adopted diagnosis criteria and time elapsed from surgery ${ }^{9-11}$. In a prospective cohort study carried out at the Brazilian National Cancer Institute (INCA-Brazil) concerning women undergoing axillary lymphadenectomy (AL), lymphedema incidence was reported as $17 \%$ in 2 years, $30 \%$ in 5 years, and $41 \%$ in 10 years $^{12,13}$. Macedo et al. ${ }^{6}$ performed an observational study comprising 933 women $(73.2 \%$ submitted to sentinel lymph node biopsy [SLB], 15.4\% submitted to SLB followed by AL, and $11.4 \%$ submitted to AL) and concluded that SLB represents an independent protective factor concerning complications, including lymphedema, when compared to $\mathrm{AL}^{14}$.

The main risk factors for lymphedema development comprise the number of removed lymph nodes, drainage chain radiotherapy, chemotherapy infusion in the upper limb ipsilateral to surgical treatment, limb infection, high body mass index (BMI), advanced age, and having developed early postoperative seroma and edema ${ }^{13,15-17}$.

Preventive lymphedema guidelines are provided by a multidisciplinary team ${ }^{18}$, as increasing limb volume can interfere with daily activities, generating physical and emotional consequences and directly impacting patient's quality of life ${ }^{19}$. Some guidelines recommend the use of repellents against insect bites, as well as avoiding trauma, burns, blood pressure measurements, and the administration of injections in the limb ipsilateral to the surgery ${ }^{10,20}$. In addition, other guidelines also comprise caution regarding excessive exposure of the ipsilateral limb to the surgery to heat, limb overload use restrictions, and recommendations against performing rapid and repetitive movements with the ipsilateral limb, as these activities increase arterial capillary ultrafiltration, which may overload the lymphatic system ${ }^{21}$.

The practice of upper limb exercises comprises another preventive guidance, as muscle contraction promoted during exercise stimulates lymphovenous limb pumping, increasing lymphatic angiomotricity and the recruitment of collateral lymphatic pathways ${ }^{18,20,22,23}$.

With the oncological treatment and surgical technique evolution, doubts have arisen concerning the real benefits of lymphedema prevention care, as well as regarding patient adherence to these guidelines. Thus, the aim of this study was to assess patient adherence to preventive lymphedema guidelines and the distribution of sociodemographic, clinical, and treatment variables according to adherence to care.

\section{METHODS}

This assessment comprises a cross-sectional study carried out at the Cancer Hospital III/INCA, Rio de Janeiro, Brazil, and was approved by the INCA Research Ethics Committee under no. CAAE 68894017.6.0000.5274.

Women diagnosed with breast cancer who underwent surgical treatment with an axillary lymph node approach (e.g., AL or SLB), with at least 5 months of surgery, and were undergoing follow-up at the Cancer Hospital III at any cancer treatment stage were included. Patients below 18 years of age, presenting disease progression and difficulties in understanding questions, were excluded.

All patients undergoing the axillary approach (e.g., AL or SLB) are monitored by the physiotherapy service preoperatively and postoperatively (first day, 1 month, 6 months, and 1 year after surgery). In these consultations, patients receive preventive guidelines for lymphedema as a routine in the institution.

Patients scheduled for routine consultations at the institution's Mastology and Oncology clinics were recruited. All patients were approached and informed about the nature of the study, objectives, risks, and benefits and they signed a free and informed consent form. A questionnaire composed of closed questions was applied in a private environment by a trained professional, and evaluation of postoperative complications (pain, limited range of motion of the shoulder ipsilateral to the surgery, infection in the affected limb, and lymphedema) was performed. Data collection was carried out from July 2017 to February 2018.

The variables used for the analysis were patient sociodemographic data (i.e., age, skin color, education, marital status, occupation, social security link, and income), clinical data (i.e., surgical laterality, BMI, clinical staging, histological type, histological grade, and side of the tumor), and treatment data (i.e., breast surgery, breast reconstruction, axillary approach, chemotherapy, radiotherapy, hormone therapy, and target therapy), which were obtained from physical and electronic medical records.

Participants were asked about the following limb care: blood pressure measurements, injection applications, use of tight objects in the upper limb ipsilateral to the surgery, limb exposure to heat (e.g., oven, stove, hot packs, sauna, and hot tubs), cuticle removal from the hand ipsilateral to the surgery, limb protection against trauma, carrying out household tasks, performing upper limb home exercises, and load bearing by the upper limb ipsilateral to the surgery (the patient was asked if she supports, carries, pulls, or pushes heavy objects with her limb). The answer options for all questions were yes or no.

Preventive care was grouped into three categories, to better assess and understand the results, as follows:

- Assistance care: The patients were asked about performing blood pressure measurement and injections in the limb ipsilateral to the surgery. Negative responses to both questions indicated adherence; 
- Limb care: The patients were asked about the use of tight objects in the upper limb ipsilateral to the surgery, limb exposure to heat, cuticle removal from the hand ipsilateral to the surgery, upper limb protection against trauma, and carrying out household chores. Positive responses regarding upper limb protection against trauma and negative responses for the other questions were categorized as care adherence;

- Exercise-related care: The patients were asked about the practice of home upper limb exercises and load bearing with the upper limb ipsilateral to the surgery. Positive responses to exercise practice and negative responses to limb load bearing categorized adherence.

Lymphedema was diagnosed through perimetry measurements performed on the day of the interview, measured bilaterally, using the elbow joint interline as the reference point. Limb circumference was measured every $7 \mathrm{~cm}$ above and below the interline, and limb volume was estimated using the truncated cone formula (Equation 1):

$\mathrm{V}=\mathrm{h} \times\left(\mathrm{C}^{2}+\mathrm{c}^{2}+\mathrm{Cc}\right) / 12 \pi$

Where:

$\mathrm{V}$ : the volume and $\mathrm{h}$ is the distance between $(\mathrm{C})$ proximal circumference and (c) distal circumference ${ }^{24,25}$.

Lymphedema was considered when the difference between the volumes of the affected limb and the contralateral limb was ${ }^{3} 10 \%$.

The evaluation of other postoperative complications was performed as follows: pain (patients were asked about the presence or absence of pain at the time of evaluation); limited range of motion of the shoulder ipsilateral to the surgery (it was requested to perform active movement of the shoulder flexion and abduction; the patients who presented any functional deficit during the performance of the movements were considered to have limited movement and those who did not present a functional deficit were considered not limited); and infection in the affected limb (participants were asked about the occurrence of any episode of infection on the affected limb after surgery and whether they received antibiotic therapy).

A descriptive analysis of patient demographic, clinical, treatments, postoperative complications variables, and main outcomes (adherence to the guidelines) was performed through a central tendency measure and data dispersion and frequency measures analyses. Differences between means were assessed using the Student's $t$-test, while differences between proportions were evaluated using the chi-square test. A significance level of $5 \%$ was considered for all assessments.

All statistical analyses were performed using the Statistical Package for Social Sciences (SPSS) 20.0 software.

Sample size was calculated considering $50 \%$ of all patients as adhering to preventive physical therapy guidelines at a significance level of $5 \%$. These parameters indicated the inclusion of 96 women in the study.

\section{RESULTS}

A total of 103 women who underwent surgical treatment with an axillary approach for breast cancer were included in this study, with a mean age of $58.4(+12.6)$. The mean time between the surgical approach and the conducted interview was 4.74 years (standard deviation 4.98), ranging from 5 months to 21 years.

Most women declared themselves white (55.3\%), 79.6\% presented over 8 years of education, $54.4 \%$ did not live with a partner, and $68.9 \%$ performed household activities as their main activity. Regarding nutritional status, $77.5 \%$ of women were classified as overweight or obese (Table 1).

Table 1. Sociodemographic, clinical, and treatment characteristics $(n=103)$.

\section{Variables}

Total N (\%)

Age

\begin{tabular}{l|l}
\hline$\leq 59$ & $53(51.5)$ \\
\hline 60 & $50(48.5)$ \\
\hline \multicolumn{2}{|l}{ Skin color } \\
\hline White & $57(55.3)$ \\
\hline Non-white & $46(44.7)$ \\
\hline
\end{tabular}

Schooling, years

\begin{tabular}{l|l}
\hline$\leq 8$ & $21(20.4)$ \\
\hline 8 & $82(79.6)$ \\
\hline
\end{tabular}

Marital status

\begin{tabular}{l|l}
\hline No partner & $56(54.4)$ \\
\hline With partner & $47(45.6)$ \\
\hline
\end{tabular}

\begin{tabular}{l|l}
\hline \multicolumn{2}{l}{ Occupation } \\
\hline Home occupation & $71(68.9)$ \\
\hline Active occupation & $32(31.1)$ \\
\hline Social security link & \\
\hline None & $44(42.7)$ \\
\hline Linked & $59(57.3)$
\end{tabular}

Income

\begin{tabular}{l|c}
\hline$<1$ minimum wage & $43(41.7)$ \\
\hline $1-3$ minimum wages & $47(45.6)$ \\
\hline$>3$ minimum wages & $13(12.6)$ \\
\hline Surgical laterality & $48(46.6)$ \\
\hline Nondominant & $50(48.5)$ \\
\hline Dominant & $5(4.9)$ \\
\hline Bilateral & Continue
\end{tabular}


Table 1. Continuation.

\section{Variables Total N (\%)} BMI

\begin{tabular}{|c|c|}
\hline Adequate & $18(22.5)$ \\
\hline Overweight & $26(32.5)$ \\
\hline Obese & $36(45.0)$ \\
\hline \multicolumn{2}{|l|}{ Clinical staging* } \\
\hline Initial $(0,1$, IIA) & $29(37.2)$ \\
\hline Advanced (IIB, IIIA, IIIB, IV) & $49(62.8)$ \\
\hline \multicolumn{2}{|l|}{ Histological type* } \\
\hline Invasive ductal carcinoma & $91(89.9)$ \\
\hline In situ ductal carcinoma & $5(4.9)$ \\
\hline Invasive lobular carcinoma & $3(2.9)$ \\
\hline Others & $3(2.9)$ \\
\hline \multicolumn{2}{|l|}{ Histological grade* } \\
\hline 1 & $6(6.5)$ \\
\hline 2 & $63(67.7)$ \\
\hline 3 & $24(25.8)$ \\
\hline \multicolumn{2}{|l|}{ Tumor side } \\
\hline Right & $48(46.6)$ \\
\hline Left & $50(48.5)$ \\
\hline Bilateral & $5(4.9)$ \\
\hline \multicolumn{2}{|l|}{ Breast surgery } \\
\hline Mastectomy & $83(80.6)$ \\
\hline Conservative & $20(19.4)$ \\
\hline \multicolumn{2}{|l|}{ Breast reconstruction } \\
\hline Yes & $31(30.1)$ \\
\hline No & $72(69.9)$ \\
\hline \multicolumn{2}{|l|}{ Axillary approach } \\
\hline Axillary lymphadenectomy & $70(68.0)$ \\
\hline Sentinel lymph node biopsy & $33(32.0)$ \\
\hline \multicolumn{2}{|l|}{ Chemotherapy } \\
\hline Yes & $88(85.4)$ \\
\hline No & $15(14.6)$ \\
\hline \multicolumn{2}{|l|}{ Radiotherapy } \\
\hline Yes & $67(65.0)$ \\
\hline No & $36(35.0)$ \\
\hline \multicolumn{2}{|l|}{ Hormone therapy } \\
\hline Yes & $82(79.6)$ \\
\hline No & $21(20.4)$ \\
\hline \multicolumn{2}{|l|}{ Target therapy } \\
\hline Yes & $18(17.5)$ \\
\hline No & $85(82.5)$ \\
\hline
\end{tabular}

BMI: body mass index; *differences in values correspond to the lack of information.
Regarding clinical characteristics, most women (62.8\%) presented advanced cancer staging (higher than IIB) and a histological type categorized as invasive ductal carcinoma (IDC) (89.9\%). Regarding treatment, $80.6 \%$ of the patients underwent mastectomies, $68.0 \%$ underwent axillary lymphadenectomies, $85.4 \%$ underwent systemic treatment with chemotherapy, $65.0 \%$ underwent radiotherapy, and $79.6 \%$ underwent hormone therapy (Table 1).

Considering postoperative complications, $48.5 \%$ of all patients reported pain in the upper limb ipsilateral to the surgery at the time of the interview, $15.5 \%$ exhibited limited shoulder range of motion, $12.6 \%$ indicated they had already had at least one episode of limb infection, and $25.2 \%$ developed lymphedema (Table 2).

Regarding the implementation of preventive lymphedema guidelines, all interviewees claimed to have received the guidelines during the postoperative period. Considering adherence to guidelines, $89.3 \%$ of all patients adhered to assistance care, $61.2 \%$ adhered to limb care, and $42.7 \%$ performed exercise-related care (Figure 1).

When evaluating adherence to care-associated factors, women who underwent chemotherapy $(\mathrm{p}=0.030)$ and AL $(\mathrm{p}=0.017)$ exhibited greater adherence to care compared to those who did not undergo these treatments. Regarding limb care adherence, non-white women $(\mathrm{p}=0.048)$ and those who underwent AL ( $p=0.025)$ adhered more frequently compared to patients who did not undergo these treatments. Considering preventive care adherence through exercise, women presenting lower education levels $(\mathrm{p}=0.013)$ and those who underwent AL $(p=0.009)$ adhered to exercise-associated guidelines more frequently (Table 3 ).

Table 2. Postoperative complications ( $n=103)$.

\begin{tabular}{l|c} 
Variables & N $(\%)$ \\
Pain & $50(48.5)$ \\
\hline Yes & $53(51.5)$ \\
\hline No & $16(15.5)$ \\
\hline Limited range of motion & $87(84.5)$ \\
\hline Yes & $13(12.6)$ \\
\hline No & $90(87.4)$ \\
\hline Affected upper limb infection & \\
\hline Yes & $26(25.2)$ \\
\hline No & $77(74.8)$ \\
\hline Lymphedema* &
\end{tabular}

*There is $10 \%$ difference in volume between the upper limbs. 


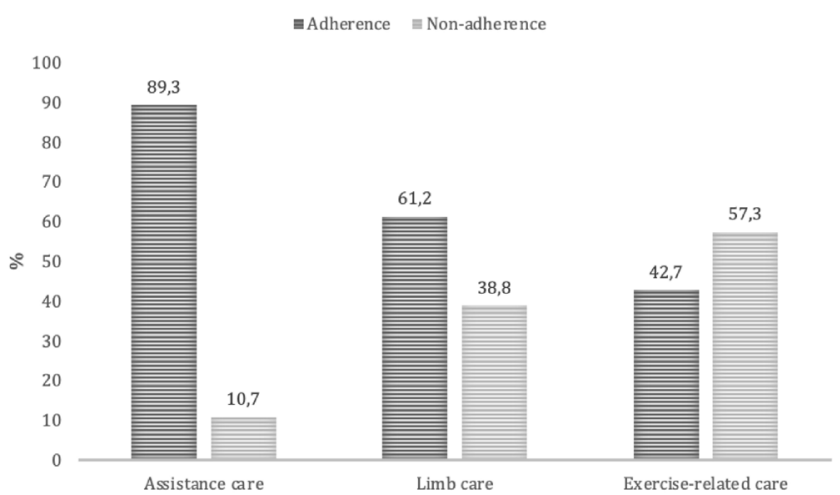

Figure 1. Patient adherence to preventive care of lymphedema guidelines.

\section{DISCUSSION}

The assessments carried out herein were performed concerning patients treated at a single breast cancer referral center. Although all patients reported having received preventive lymphedema guidance by the hospital's physiotherapy team on the first postoperative day and indicated that they understood its importance during the interview, only $89.3 \%$ of the patients adhered to assistance care guidelines, $61.2 \%$ to limb care guidelines, and $42.7 \%$ to exercise-related care guidelines. Adherenceassociated factors were related to cancer treatment and patient demographic characteristics.

Despite the low adherence to exercise-related care, $74.8 \%$ of the patients did not present upper limb lymphedema, $48.5 \%$

Table 3. Distribution of sociodemographic, clinical, and treatment variables according to adherence to care.

\begin{tabular}{|c|c|c|c|c|c|c|c|c|c|}
\hline \multirow[b]{2}{*}{ Variables } & \multicolumn{3}{|c|}{ Assistance care } & \multicolumn{3}{|c|}{ Limb care } & \multicolumn{3}{|c|}{ Exercise-related care } \\
\hline & $\begin{array}{c}\text { Yes } \\
\text { N (\%) }\end{array}$ & $\begin{array}{l}\text { No } \\
\text { N (\%) }\end{array}$ & $\mathbf{p}^{*}$ & $\begin{array}{c}\text { Yes } \\
\text { N (\%) }\end{array}$ & $\begin{array}{c}\text { No } \\
\text { N (\%) }\end{array}$ & $\mathbf{p}^{*}$ & $\begin{array}{c}\text { Yes } \\
\text { N (\%) }\end{array}$ & $\begin{array}{c}\text { No } \\
\text { N (\%) }\end{array}$ & $\mathbf{p}^{*}$ \\
\hline \multicolumn{10}{|l|}{ Skin color } \\
\hline White & $50(54.3)$ & $7(63.6)$ & \multirow{2}{*}{0.558} & $30(47.6)$ & $27(67.5)$ & \multirow{2}{*}{0.048} & $21(47.7)$ & $36(61.0)$ & \multirow{2}{*}{0.180} \\
\hline Non-white & $42(45.7)$ & $4(36.4)$ & & $33(52.4)$ & $13(32.5)$ & & $23(52.3)$ & $23(39.0)$ & \\
\hline \multicolumn{10}{|l|}{ Occupation } \\
\hline Home occupation & $64(69.6)$ & $7(63.6)$ & \multirow{2}{*}{0.668} & $41(65.1)$ & $30(75.0)$ & \multirow{2}{*}{0.289} & $27(61.4)$ & $44(74.6)$ & \multirow{2}{*}{0.152} \\
\hline Active occupation & $28(30.4)$ & $4(36.4)$ & & $22(34.9)$ & $10(25.0)$ & & $17(38.6)$ & $15(25.4)$ & \\
\hline \multicolumn{10}{|l|}{ Social security link } \\
\hline None & $38(41.3)$ & $6(54.5)$ & \multirow{2}{*}{0.401} & $31(49.2)$ & $13(32.5)$ & \multirow{2}{*}{0.095} & $23(52.3)$ & $21(35.6)$ & \multirow{2}{*}{0.090} \\
\hline Linked & $54(58.7)$ & $5(45.5)$ & & $32(50.8)$ & $27(67.5)$ & & $21(47.7)$ & $38(64.4)$ & \\
\hline \multicolumn{10}{|l|}{ Schooling, years } \\
\hline$\leq 8$ & $21(22.8)$ & $0(0.0)$ & \multirow{2}{*}{0.076} & $14(22.2)$ & $7(17.5)$ & \multirow{2}{*}{0.562} & $14(31.8)$ & 7 (11.9) & \multirow{2}{*}{0.013} \\
\hline 8 & $71(77.2)$ & $11(100.0)$ & & $49(77.8)$ & $33(82.5)$ & & $30(68.2)$ & $52(88.1)$ & \\
\hline \multicolumn{10}{|l|}{$\mathrm{BMI}$} \\
\hline Adequate & $16(22.8)$ & $2(20.0)$ & \multirow{3}{*}{0.118} & 9 (18.4) & $9(29.0)$ & \multirow{3}{*}{0.535} & $6(18.2)$ & $12(25.5)$ & \multirow{3}{*}{0.583} \\
\hline Overweight & $20(28.6)$ & $6(60.0)$ & & $17(34.7)$ & $9(29.0)$ & & $10(30.3)$ & $16(34.0)$ & \\
\hline Obese & $34(48.6)$ & $2(20.0)$ & & $23(46.9)$ & $13(42.0)$ & & $17(51.5)$ & $19(40.4)$ & \\
\hline \multicolumn{10}{|l|}{ Clinical staging } \\
\hline Initial $(0,1,|| A)$ & $28(38.9)$ & $1(16.7)$ & \multirow{2}{*}{0.279} & $18(39.1)$ & $11(34.4)$ & \multirow{2}{*}{0.669} & $9(27.3)$ & $20(44.4)$ & \multirow{2}{*}{0.121} \\
\hline Advanced (IIB, IIIA, IIIB, IV) & $44(61.1)$ & $5(83.3)$ & & $28(60.9)$ & $21(65.6)$ & & $24(72.7)$ & $25(55.6)$ & \\
\hline \multicolumn{10}{|l|}{ Surgical laterality } \\
\hline Nondominant & $44(47.8)$ & $4(36.4)$ & \multirow{3}{*}{0.662} & $28(44.4)$ & $20(50.0)$ & & $17(38.6)$ & $31(52.5)$ & \\
\hline Dominant & $44(47.8)$ & $6(54.5)$ & & $31(49.2)$ & $19(47.5)$ & 0.630 & $25(56.8)$ & $25(42.4)$ & 0.342 \\
\hline Bilateral & $4(4.3)$ & $1(9.1)$ & & $4(6.3)$ & $1(2.5)$ & & $2(4.5)$ & $3(5.1)$ & \\
\hline Breast surgery & & & & & & & & & \\
\hline Mastectomy & $73(79.3)$ & $10(90.9)$ & 020 & $52(82.5)$ & $31(77.5)$ & 0 & $38(86.4)$ & $45(76.3)$ & תم 20 \\
\hline Conservative & $19(20.7)$ & $1(9.1)$ & 0.000 & $11(17.5)$ & $9(22.5)$ & 0.02 & $6(13.6)$ & $14(23.7)$ &.$\angle 00$ \\
\hline
\end{tabular}


Table 3. Distribution of sociodemographic, clinical, and treatment variables according to adherence to care.

\begin{tabular}{|c|c|c|c|c|c|c|c|c|c|}
\hline \multirow[b]{2}{*}{ Variables } & \multicolumn{3}{|c|}{ Assistance care } & \multicolumn{3}{|c|}{ Limb care } & \multicolumn{3}{|c|}{ Exercise-related care } \\
\hline & $\begin{array}{c}\text { Yes } \\
\text { N (\%) }\end{array}$ & $\begin{array}{c}\text { No } \\
\text { N (\%) }\end{array}$ & $\mathbf{p}^{*}$ & $\begin{array}{c}\text { Yes } \\
\text { N (\%) }\end{array}$ & $\begin{array}{c}\text { No } \\
\text { N (\%) }\end{array}$ & $\mathbf{p}^{*}$ & $\begin{array}{c}\text { Yes } \\
\text { N (\%) }\end{array}$ & $\begin{array}{c}\text { No } \\
\text { N (\%) }\end{array}$ & $\mathrm{p}^{*}$ \\
\hline \multicolumn{10}{|l|}{ Breast reconstruction } \\
\hline Yes & $25(27.2)$ & $6(54.5)$ & \multirow{2}{*}{0.061} & $15(23.8)$ & $16(40.0)$ & \multirow{2}{*}{0.081} & $10(22.7)$ & $21(35.6)$ & \multirow{2}{*}{0.159} \\
\hline No & $67(72.8)$ & $5(45.5)$ & & $48(76.2)$ & $24(60.0)$ & & $34(77.3)$ & $38(64.4)$ & \\
\hline \multicolumn{10}{|l|}{ Axillary approach } \\
\hline Axillary lymphadenectomy & $66(71.7)$ & $4(36.4)$ & \multirow{2}{*}{0.017} & $48(76.2)$ & $22(55.0)$ & \multirow{2}{*}{0.025} & $36(81.8)$ & $34(57.6)$ & \multirow{2}{*}{0.009} \\
\hline Sentinel lymph node biopsy & $26(28.3)$ & $7(63.6)$ & & $15(23.8)$ & $18(45.0)$ & & $8(18.2)$ & $25(42.4)$ & \\
\hline \multicolumn{10}{|l|}{ Chemotherapy } \\
\hline Yes & $81(88.0)$ & $7(63.6)$ & \multirow{2}{*}{0.030} & $56(88.9)$ & $32(80.0)$ & \multirow{2}{*}{0.213} & $38(86.4)$ & $50(84.7)$ & \multirow{2}{*}{0.818} \\
\hline No & $11(12.0)$ & $4(36.4)$ & & $7(11.1)$ & $8(20.0)$ & & $6(13.6)$ & $9(15.3)$ & \\
\hline \multicolumn{10}{|l|}{ Radiotherapy } \\
\hline Yes & $62(67.4)$ & $5(45.5)$ & \multirow{2}{*}{0.149} & $41(65.1)$ & $26(65.0)$ & \multirow{2}{*}{0.993} & $30(68.2)$ & $37(62.7)$ & \multirow{2}{*}{0.565} \\
\hline No & $30(32.6)$ & $6(54.5)$ & & $22(34.9)$ & $14(35.0)$ & & $14(31.8)$ & $22(37.3)$ & \\
\hline
\end{tabular}

BMI: body mass index; Values in bold indicate $p<0.05$; * $p$-value: the $\chi^{2}$ test.

reported pain in the upper limb ipsilateral to the surgery at the time of the interview, and $15.5 \%$ exhibited limited shoulder range of motion, all symptoms directly related to overload and low limb exercise ${ }^{26,27}$. Sherman et al. ${ }^{17}$ observed that guideline adherence increased from $79 \%$ to $86 \%$ from the first to the 6-month postoperative assessment and was maintained in the follow-up until 12 months after surgery. In this study, the mean time between surgical treatment and interview was 4.74 years.

Regarding care, adequate adherence $(89.3 \%)$ was probably maintained due to an association between health professional conduct and more sporadic events, such as blood pressure measurements and punctures or injections in the limb ipsilateral to surgical treatment. The hospital unit where the study was carried out, being a reference hospital in the treatment of breast cancer, has a well-established routine regarding the nonperformance of these procedures in the upper limb ipsilateral to the surgery whenever possible ${ }^{18,28}$.

In this study, most women presenting advanced clinical staging and underwent radiotherapy adhered to assistance care, albeit with no statistical significance. Statistical significances were observed only between this type of care and for patients undergoing chemotherapy. Studies have observed that both radiotherapy and chemotherapy present risks concerning lymphedema development ${ }^{10,22,29-31}$. In a Brazilian cohort followed at the same hospital unit, advanced breast cancer stage, lymphatic drainage chain radiotherapy, and chemotherapy administration in the upper limb ipsilateral to surgery increase the risk for limb lymphedema ${ }^{13}$.

Concerning limb care, most patients followed the provided guidelines. Among patients who followed limb care, $76.2 \%$ underwent axillary emptying. According to the literature, patients who undergo AL display a higher risk of developing lymphedema compared to those who undergo SLB ${ }^{10,14,32,33}$.

At present, significant doubts concerning the real need to follow so many preventive guidelines are in place, as well as which guidelines are in fact important, and which should be maintained. Some studies have not reported associations between ipsilateral upper limb volume increase and venipuncture surgery, injections, or blood pressure measurements performed in this $\operatorname{limb}^{20,34}$. Ferguson et al. ${ }^{20}$ also reported no association between lymphedema and upper limb trauma. In contrast, when evaluating associations between lymphedema and infection, $\mathrm{Fu}^{26}$ stated that women presenting upper limb infection are more likely to develop lymphedema, and Ferguson et al. ${ }^{20}$ noted that infection increases risks for developing lymphedema. Other assessments have also reported significant associations between infection in the limb ipsilateral to surgery and lymphedema ${ }^{12,31,35,36}$.

Regarding exercise-related care, over half of the patients (57.3\%) reported not adhering to the recommended guidelines, bearing weight, and not practicing regular upper limb exercises. The literature reports that physical exercise has emerged as an important survival recommendation and important ally in lymphedema prevention. Upper limb exercise is an important 
strategy in complex physical therapy as well as a useful tool in long-term lymphedema management. Exercise programs that include aerobic and resistance exercise do not trigger or exacerbate lymphedema ${ }^{31,36}$. In addition, there is a consensus that women who undergo surgical breast cancer treatment benefit from resistance exercise through physical function maintenance and recovery in the affected upper limb, as well as a healthy body composition ${ }^{37,38}$. Concerning patients who adhered to this type of care, most presented less than 8 years of education and had undergone $\mathrm{AL}$, demonstrating greater adherence to exercise practice and care regarding weight bearing with the upper limb ipsilateral to the surgery.

Axillary lymphadenectomy is the most consistent risk factor for upper limb lymphedema following breast cancer treatment ${ }^{12,13,31}$, which may explain the greater upper limb exercise adherence of the patients assessed in this study. Jammallo et al. ${ }^{39}$ demonstrated that women who underwent AL presented greater postoperative fear compared to those who underwent SLB or who did not receive axillary surgery. Similar findings were also reported by McLaughlin et al., in which persistent concern regarding lymphedema was reported by $75 \%$ of women who underwent AL and by $50 \%$ of those who underwent SLB at 12 months of follow-up.

Lu et al. carried out a clinical trial in which patients undergoing surgical breast cancer treatment were randomized to either only receive guidance on preventive lymphedema care or receive both physical therapy and limb care guidance, and also a control group, which did not receive any orientation or undergo physiotherapy. The patients were followed up for 1 year, and the authors observed that physical therapy associated with preventive care guidance displayed a $65 \%$ reduced risk of developing lymphedema, but did not observe any benefits concerning the exclusive guidelines for lymphedema prevention, justifying that the patients who received the guidelines only did not adhere to care and stating that poor adherence to self-care programs is capable of preventing treatment success.

This study has a limitation that needs to be considered. The research did not assess the relationship between adherence and surgery time in order to observe whether patients who operated more recently adhered more to the recommendations than those who operated many years ago.

Physical therapy aims to prevent possible postoperative complications and promote comprehensive care, aiming at better quality of life for the patients. To this end, all patients diagnosed with breast cancer must have access to a physical therapy routine, monitored during all cancer treatment stages, as well as in the follow-up period ${ }^{18,40}$.

The physiotherapy team must be attentive to the way it presents preventive lymphedema guidelines, to generate more information and less patient anguish, consequently improving patient care. The physical therapy approach must always seek adaptations and never prohibitions, providing understanding and cooperation and sharing self-care responsibility with all patients.

Further studies should be carried out with a higher number of participants and considering Brazilian population characteristics, in order to understand which guidelines are in fact necessary and, thus, generate less patient anguish and limitations.

\section{CONCLUSIONS}

Although the patients evaluated herein stated that they received preventive guidelines for lymphedema, this study observed difficulties concerning adhesion to exercise-related care. The guidelines presenting the greatest adherence were those associated with assistance care and limb care. Despite the low adherence to exercise-associated care, $74.8 \%$ of the patients did not present upper limb lymphedema.

Patients who underwent chemotherapy presented greater adherence to care, and non-white patients adhered the most to limb care. Women who underwent AL exhibited greater adherence to all types of care and those presenting less education levels more frequently adhered to the guidelines for exercise-associated care for the upper limb ipsilateral to the surgery.

\section{AUTHORS' CONTRIBUTIONS}

E.A.N.F.: Conceptualization, Investigation, Methodology, Supervision, Validation, Visualization, Writing - original draft, Writing - review and editing; F.O.M.: Conceptualization, Data curation, Formal analysis, Investigation, Methodology, Project administration, Supervision, Validation, Visualization, Writing - original draft, Writing - review and editing; R.M.C.: Validation, Visualization, Writing - original draft, Writing - review and editing; M.B.A.L.: Conceptualization, Investigation, Methodology; L.O.M.: Conceptualization, Investigation, Methodology; S.S.A.: Formal analysis; A.B.: Formal analysis, Writing - review and editing.

\section{REFERENCES}

1. Instituto Nacional de Câncer José Alencar Gomes da Silva. Estimativa 2020: incidência de câncer no Brasil. Rio de Janeiro: INCA; 2019.
2. Globocan. The Global Cancer Observatory [Internet]. Globocan; 2020 [cited on Feb 1, 2021]. Avaiable at: https://gco. iarc.fr/today 
3. Instituto Nacional de Câncer José Alencar Gomes da Silva. A situação do câncer de mama no Brasil: síntese de dados dos sistemas de informação. Rio de Janeiro: INCA; 2019.

4. Fabro EAN, Bergmann A, Amaral e Silva B, Padula Ribeiro AC, Souza Abrahão K, Ferreira MGCL, et al. Post-mastectomy pain syndrome: incidence and risks. Breast. 2012;21(3):321-5. https://doi.org/10.1016/j.breast.2012.01.019

5. Abrahão KS, Bergmann A, Aguiar SS, Thuler LC. Determinants of advanced stage presentation of breast cancer in 87,969 Brazilian women. Maturitas. 2015;82(4):365-70. https://doi. org/10.1016/j.maturitas.2015.07.021

6. Macedo FO, Bergmann A, Koifman RJ, Torres DM, Costa RM, da Silva IF. Axillary surgery in breast cancer: acute postoperative complications in a hospital cohort of women of Rio de Janeiro, Brazil. Mastology. 2018;28(2):80-6. https://doi.or g/10.29289/2594539420180000377

7. McLaughlin SA, Bagaria S, Gibson T, Arnol M, Diehl N, Crook $\mathrm{J}$, et al. Trends in risk reduction practices for the prevention of lymphedema in the first 12 months after breast cancer surgery. J Am Coll Surg. 2013;216(3):380-9. https://doi.org/10.1016/j. jamcollsurg.2012.11.004

8. Executive Committee of the International Society of Lymphology. The diagnosis and treatment of peripheral lymphedema: 2020 Consensus Document of the International Society of Lymphology. Lymphology. 2020;53(1):3-19.

9. Bergmann A, Mattos IE, Koifman RJ. Incidence and prevalence of lymphedema after breast cancer surgery: literature review. Rev Bras Cancerol. 2007;53(4):461-70.

10. DiSipio T, Rye S, Newman B, Hayes S. Incidence of unilateral arm lymphoedema after breast cancer: a systematic review and meta-analysis. Lancet Oncol. 2013;14(6):500-15. https:// doi.org/10.1016/S1470-2045(13)70076-7

11. Torgbenu E, Luckett T, Buhagiar MA, Chang S, Phillips JL. Prevalence and incidence of cancer related lymphedema in low and middle-income countries: a systematic review and metaanalysis. BMC Cancer. 2020;20:604. https://doi.org/10.1186/ s12885-020-07079-7

12. Bevilacqua JL, Kattan MW, Changhong Y, Koifman S, Mattos IE, Koifman RJ, et al. Nomograms for predicting the risk of arm lymphedema after axillary dissection in breast cancer. Ann Surg Oncol. 2012;19(8):2580-9. https://doi.org/10.1245/s10434012-2290-x

13. Ribeiro Pereira ACP, Koifman RJ, Bergmann A. Incidence and risk factors of lymphedema after breast cancer treatment: 10 years of follow-up. Breast. 2017;36:67-73. https://doi. org/10.1016/j.breast.2017.09.006

14. Macedo FO. Abordagem cirúrgica axilar no câncer de mama estadiamento clínico T1- T2N0M0: complicações pósoperatórias e sobrevida em uma coorte hospitalar de mulheres do Rio de Janeiro [dissertation]. Rio de Janeiro (RJ): Escola Nacional de Saúde Pública Sergio Arouca - Fundação Oswaldo Cruz; 2015.

15. Jammallo LS, Miller CL, Singer M, Horick NK, Skolny MN, Specht MC, et al. Impact of body mass index and weight fluctuation on lymphedema risk in patients treated for breast cancer. Breast Cancer Res Treat. 2013;142(1):59-67. https://doi. org/10.1007/s10549-013-2715-7
16. Warren LE, Miller CL, Horick N, Skolny MN, Jammallo LS, Sadek BT, et al. The impact of radiation therapy on the risk of lymphedema after treatment for breast cancer: a prospective cohort study. Int J Radiat Oncol Biol Phys. 2014;88(3):565-71. https://doi.org/10.1016/j.jirobp.2013.11.232

17. Sherman KA, Miller SM, Roussi P, Taylor A. Factors predicting adherence to risk management behaviors of women at increased risk for developing lymphedema. Support Care Cancer. 2015;23(1):61-9. https://doi.org/10.1007/s00520-0142321-1

18. Fabro EAN, Costa RM, de Oliveira JF, Lou MBA, Torres DM, Ferreira FO, et al. Care physical therapy in control of secondary lymphedema treatment of breast cancer: routine Cancer Hospital III/National Cancer Institute. Rev Bras Mastologia. 2016;26(1):4-8. https://doi.org/10.5327/Z201600010002RBM

19. Ahn S, Port ER. Lymphedema precautions: Time to abandon old practices? J Clin Oncol. 2016;34(7):655-8. https://doi. org/10.1200/JCO.2015.64.9574

20. Ferguson CM, Swaroop MN, Horick N, Skolny MN, Miller CL, Jammallo LS, et al. Impact of ipsilateral blood draws, injections, blood pressure measurements, and air travel on the risk of lymphedema for patients treated for breast cancer. J Clin Oncol. 2016;34(7):691-8. https://doi.org/10.1200/JCO.2015.61.5948

21. Asdourian MS, Skolny MN, Brunelle C, Seward CE, Salama L, Taghian AG. Precautions for breast cancer-related lymphoedema: risk from air travel, ipsilateral arm blood pressure measurements, skin puncture, extreme temperatures, and cellulitis. Lancet Oncol. 2016;17(9):e392-405. https://doi. org/10.1016/S1470-2045(16)30204-2

22. Paramanandam VS, Roberts D. Weight training is not harmful for women with breast cancer-related lymphoedema: a systematic review. J Physiother. 2014;60(3):136-43. https://doi. org/10.1016/j.jphys.2014.07.001

23. Lu SR, Hong RB, Chou W, Hsiao PC. Role of physiotherapy and patient education in lymphedema control following breast cancer surgery. Ther Clin Risk Manag. 2015;2015(11):319-27. https://doi.org/10.2147/TCRM.S77669

24. Bergman A, Mattos IE, Koifman RJ. Diagnosis of lymphedema: analysis of the methods used in the evaluation of the upper limb in women undergoing axillary linfadenectomy for breast cancer treatment. Rev Bras Cancerol. 2004;50(4):311-20.

25. Torres Lacomba M, Yuste Sánchez MJ, Zapico Goñi A, Prieto Merino D, Mayoral del Moral O, Cerezo Téllez E, et al. Effectiveness of early physiotherapy to prevent lymphoedema after surgery for breast cancer: randomized, single blinded, clinical trial. BMJ. 2010;340:b5396. https://doi.org/10.1136/bmj. b5396

26. Fu MR. Breast cancer-related lymphedema: Symptoms, diagnosis, risk reduction, and management. World J Clin Oncol. 2014;5(3):241-7. https://doi.org/10.5306/wjco.v5.i3.241

27. Togawa K, Ma H, Smith AW, Neuhouser ML, George SM, Baumgartner KB, et al. Self-reported symptoms of arm lymphedema and health-related quality of life among female breast cancer survivors. Sci Rep. 2021;11(1):10701. https://doi. org/10.1038/s41598-021-89055-0

28. Bergmann A. Prevalência de linfedema subsequente a tratamento cirúrgico para câncer de mama no Rio de Janeiro 
[dissertation]. Rio de Janeiro: Fundação Oswaldo Cruz, Escola de Saúde Pública; 2000.

29. ByunHK,ChangJS,ImSH,Kirova YM,Arsene-HenryA,ChoiSH, et al. Risk of lymphedema following contemporary treatment for breast cancer: an analysis of 7,617 consecutive patients from a multidisciplinary perspective. Ann Surg. 2021;274(1):170-8. https://doi.org/10.1097/SLA.0000000000003491

30. Zhang Z, Zhang X, Chen S, Jiang J, Qi R, Zhang X, et al. Taxane-based chemotherapy and risk of breast cancer-related lymphedema: Protocol for a systematic review and metaanalysis. Medicine (Baltimore). 2019;98(30):e16563. https://doi. org/10.1097/MD.0000000000016563

31. McLaughlin SA, Brunelle CL, Taghian A. Breast cancerrelated lymphedema: risk factors, screening, management, and the impact of locoregional treatment. J Clin Oncol. 2020;38(20):2341-50. https://doi.org/10.1200/JCO.19.02896

32. Zou L, Liu FH, Shen PP, Hu Y, Liu XQ, Xu YY, et al. The incidence and risk factors of related lymphedema for breast cancer survivors post-operation: a 2-year follow-up prospective cohort study. Breast Cancer. 2018;25(3):309-14. https://doi. org/10.1007/s12282-018-0830-3

33. Galimberti V, Cole BF, Viale G, Veronesi P, Vicini E, Intra M, et al. Axillary dissection versus no axillary dissection in patients with breast cancer and sentinel-node micrometastases (IBCSG 23-01): 10-year follow-up of a randomised, controlled phase 3 trial. Lancet Oncol. 2018;19(10):1385-93. https://doi. org/10.1016/S1470-2045(18)30380-2

34. Asdourian MS, Swaroop MN, Sayegh HE, Brunelle CL, Mina AI, Zheng $\mathrm{H}$, et al. Association between precautionary behaviors and breast cancer-related lymphedema in patients undergoing. J Clin Oncol. 2017;35(35):3934-41. https://doi. org/10.1200/JCO.2017.73.7494

35. Showalter SL, Brown JC, Cheville AL, Fisher CS, Sataloff D, Schmitz KH. Lifestyle risk factors associated with arm swelling among women with breast cancer. Ann Surg Oncol. 2013;20(3):842-9. https://doi.org/10.1245/s10434012-2631-9

36. Gillespie TC, Sayegh HE, Brunelle CL, Daniell KM, Taghian AG. Breast cancer-related lymphedema: risk factors, precautionary measures, and treatments. Gland Surg. 2018;7(4):379-403. https://doi.org/10.21037/gs.2017.11.04

37. Hasenoehrl T, Keilani M, Palma S, Crevenna R. Resistance exercise and breast cancer related lymphedema - a systematic review update. Disabil Rehabil. 2020;42(1):26-35. https://doi.or $\mathrm{g} / 10.1080 / 09638288.2018 .1514663$

38. Keilani M, Hasenoehrl T, Neubauer M, Crevenna R. Resistance exercise and secondary lymphedema in breast cancer survivors-a systematic review. Support Care Cancer. 2016;24(4):1907-16. https://doi.org/10.1007/ s00520-015-3068-z

39. Jammallo LS, Miller CL, Horick NK, Skolny MN, O’Toole J, Specht MC, et al. Factors associated with fear of lymphedema after treatment for breast cancer. Oncol Nurs Forum. 2014;41(5):473-83. https://doi.org/10.1188/14. ONF.473-483

40. Stout NL, Binkley JM, Schmitz KH, Andrews K, Hayes $\mathrm{SC}$, Campbell KL, et al. A prospective surveillance model for rehabilitation for women with breast cancer. Cancer. 2012;118(8 Suppl.):2191-200. https://doi.org/10.1002/ cncr. 27476 